\title{
CORRIGENDUM
}

\section{Regional Integration and Ceramic Consumption in the Border Region of Bolivia and Argentina (ca. AD 1000-1450) - CORRIGENDUM}

\author{
Ester Echenique, Axel E. Nielsen, Florencia Avila, and William Gilstrap
}

DOI:10.1017/laq.2020.77. Published online by Cambridge University Press, November 26, 2020.

ligure 7 in this article (Echenique et al. 2020) was incorrect as originally published. Following is the correct figure.

\section{Reference Cited}

Echenique, Ester, Axel E. Nielsen, Florencia Avila, and William Gilstrap

2020 Regional Integration and Ceramic Consumption in the Border Region of Bolivia and Argentina (ca. AD 1000-1450). Latin American Antiquity 32:99-119. DOI:10.1017/laq.2020.77. 
A

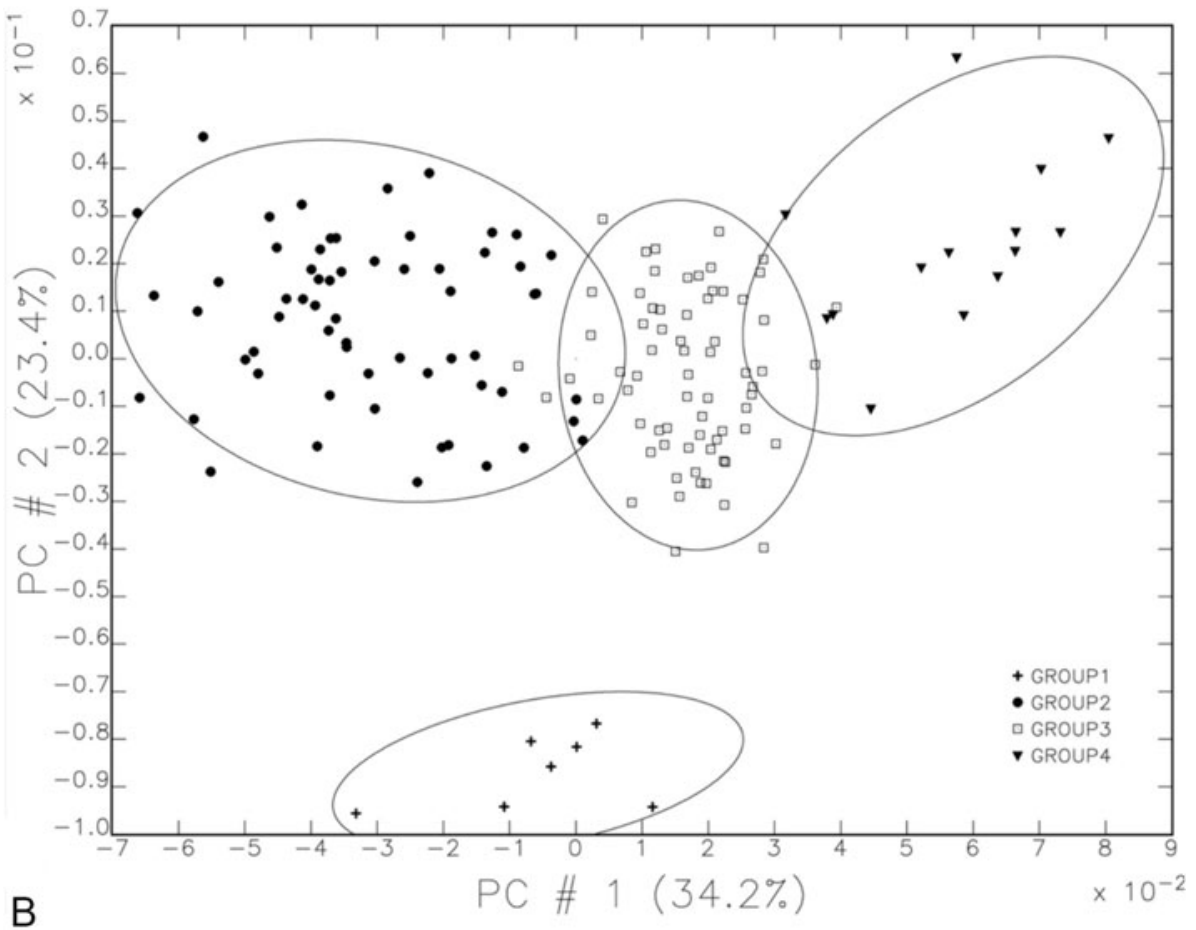

B

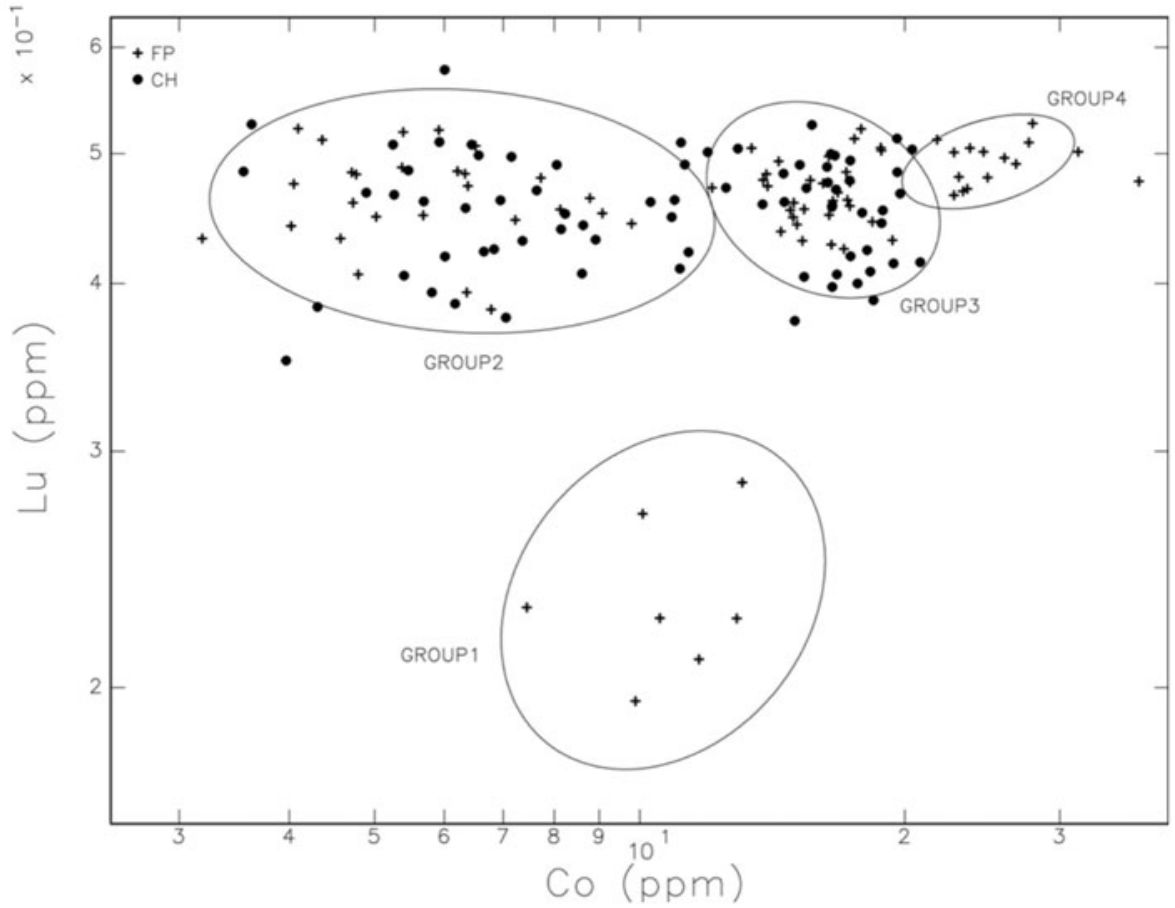

